\title{
糖尿病患者の身体活動量評価としての IPAQ日本語版に扔ける妥当性の検討
}

\author{
Examination of the Validity of the Japanese Version of the IPA Questionnaire for the \\ Evaluation of the Physical Activity of Diabetes Patients
}

\begin{abstract}
村野 勇 ${ }^{1)}$ 浅川 育世 ${ }^{2}$ 水上 昌文 ${ }^{2)}$ 瀧原 純 ${ }^{1)}$
ISAMU MURANO ${ }^{1)}$, YASUTSUGU ASAKAWA ${ }^{2)}$, MASAFUMI MIZUKAMI ${ }^{2)}$, JUN TAKIHARA ${ }^{1)}$

${ }^{1)}$ Department of Rehabilitation, Tsuchiura Kyodo General Hospital: 11-7 Manabeshinmachi, Tsuchiura-City, Ibaraki, 300-0053, Japan.TEL+81 29-823-3111E-mail: rehabilitation@tkgh.jp

${ }^{2)}$ Department of Physical Therapy, Faculty of Health Science, Ibaraki Prefectural University of Health Sciences
\end{abstract}

Rigakuryoho Kagaku 28(1): 101-104, 2013. Submitted Jul. 20, 2012. Accepted Sep. 25, 2012.

\begin{abstract}
Purpose] We investigated whether the International Physical Activity Questionnaire (IPAQ) was valid for use in assessing the physical activity levels of diabetes patients, who are expected to have reduced physical activity. [Subjects] The subjects were 16 type 2 diabetes mellitus patients. [Method] Using Pearson's correlation coefficient and Student's t-test we investigated the correspondence of 1-week exercise energy consumption calculated from the Short Version of the Japanese IPAQ, and 1-week exercise energy consumption calculated by a Suzuken Lifecorder GS/Me. [Results] We found no significant difference between the two measures according to the Student's $\mathrm{t}$-test result, and the correlation coefficient for the two measures was, $r=0.69$. [Conclusion] The level of physical activity of diabetes patients calculated from IPAQ was confirmed and validated against the level of physical activity measured by Lifecorder.
\end{abstract}

Key words: diabetes mellitus, physical activity level, International Physical Activity Questionnaire

要旨：〔目的〕身体活動量の低下が予測される糖尿病患者の身体活動量評価への活用を目的に，国際標準化身体活動 質問表（以下 IPAQ）の妥当性を検討した。〔対象〕 2 型糖尿病患者 16 人（男性 9 人，女性 7 人）を対象とした。〔方 法】スズケン社製生活習慣記録機ライフコーダ GS/Me で算出した 1 週間の運動消費エネルギーと IAPQ 日本語版の Short Versionから算出される 1 週間の運動消費エネルギーとの対応ある $\mathrm{t}$ 検定およびPearsonの相関分析を行った。〔結 果]対応ある $\mathrm{t}$ 検定の結果, 両者の間で有意な差を認めなかった。 また両変数間の相関係数は $\mathrm{r}=0.69$ であった。〔結語〕 糖尿病患者において IPAQ から算出した身体活動量はライフコーダで算出した身体活動量との間に妥当性を確認でき た。

キーワード : 糖尿病, 身体活動量, 国際標準化身体活動質問表

\footnotetext{
1) 総合病院土浦協同病院 リハビリテーション部:茨城県土浦市真鍋新町 11-7 ( ₹ 300-0053) TEL 029-823-3111

2) 茨城県立医療大学 保健医療学部 理学療法学科 


\section{I. はじめに}

糖尿病患者数は本邦のみならず全世界的に増加傾向に ある。世界保健機構（World Health Organization：以下 WHO）1)によれば, 2030 年には約 3 億 6600 万人にまで 達することが予測されており，拡大防止に向けた世界的 な取り組みが求められている2)。糖尿病は慢性疾患とし ての内部障害に位置づけられ, 血糖コントロールによって 合併症の予防やQOLの維持向上を図り, 社会生活を行っ ていくことが重要である。血糖コントロールに対する治 療としては食事療法と運動療法が基本であり, 運動療法 はその重要性が認められ, 安全かつ有効な方法で個人の 身体活動量を向上させることが可能である．糖尿病患者 の身体活動量を向上させることは，血糖コントロールだ けでなく虚血性脳卒中の発症率減少 ${ }^{3)}$, 心血管心疾患, 全死因死亡率減少 4 ,5) に効果のあることが明らかにされ ている。しかしながら糖尿病患者においては非罹病者と 比べ身体不活動状態にあることが多い6-8)。 そのため, 糖尿病患者の身体活動量を評価し, それを規定している 要因を明らかにすることで身体活動を高めるためのより 有効な介入を計画することが必要である9,10).

身体活動量の評価手段の一つとして質問紙による評価 方法があるが, 従来のものはそれぞれの調査目的に応じ て開発されており，言語や生活習慣のことなる国・地域 において，身体活動量を国際比較するには適当ではない とされる11)，そこで，世界統一基準で身体活動量を評 価するためWHOワーキンググループは国際標準化身体 活 動 質 問 表 (International Physical Activity Questionnaire：以下IPAQ）11,12)を作成し，これまでに
18 歳から 65 歳以上の高齢者 ${ }^{13)}$ に対し 12 ヶ国で実証さ れた. IPAQは，1週間における高強度および中等度の 身体活動を行う日数および時間を質問する. Long Version（以下 LV）と Short Version（以下 SV）があり， 1 週間の運動消費エネルギー (kcal)の算出ができる。 LVは 仕事中, 移動中, 家庭内, レジャータイムなど生活場面 について質問し， SVは，強度別のみで質問する，LVと $\mathrm{SV}$ との相関は高く $(\mathrm{rs}=0.80){ }^{11)}$, 質問項目の少ない $\mathrm{SV}$ が, 研究協力者への負担が少なく大規模調査や高齢者を 対象とした調査には適切だと思われる。IPAQについて は日本語版が作成され, 平均年齢 20 歳代から 30 歳代の 健常な若年者では信頼性と妥当性が検証されている 11,14)が，実際の糖尿病患者での検討は未だなされてい ない，そこで今回，高齢者を含め，また身体活動量の低 下も予測される糖尿病患者の身体活動量評価への適用の 検討が可能か, IPAQの妥当性について検討した.

\section{II. 対象と方法}

\section{1. 対象}

本研究の研究協力者は, 2010 年 8 月 1 日から 2011 年 9 月 30 日までの調査期間内で, 総合病院土浦協同病院の 内分泌内科に通院している2型糖尿病患者である．選定 基準として糖尿病と診断後, 生活習慣改善に対する指導 を受け6ヶ月以上経過し, 療養行動を実施されている者 調査時に過去 6 ケ月以内で大きく生活習慣を変えるライ フイベントが発生していない者, 身体的または医学的に 身体活動の著明な制限が確認されていない者16名とした。 対象者の内訳を表 1 に示す.

表 1 研究協力者の内訳

\begin{tabular}{|c|c|c|c|c|c|c|}
\hline 症例 & $\begin{array}{l}\text { 年齢 } \\
\text { (歳) }\end{array}$ & $\begin{array}{c}\text { 性別 } \\
\text { (男 /女) }\end{array}$ & $\begin{array}{c}\text { BMI } \\
\left(\mathrm{kg} / \mathrm{m}^{2}\right)\end{array}$ & $\begin{array}{l}\text { 罹患歴 } \\
\text { (ヶ月) }\end{array}$ & $\begin{array}{c}\text { 職業 } \\
(\text { 有 } / \text { 無) }\end{array}$ & $\begin{array}{l}\text { HbAlc } \\
\text { (NGSP) }\end{array}$ \\
\hline $\mathrm{A}$ & 64 & 女 & 30 & 454 & 無 & 8.6 \\
\hline $\mathrm{B}$ & 52 & 女 & 18.7 & 6 & 有 & 10.6 \\
\hline $\mathrm{C}$ & 74 & 男 & 28.4 & 6 & 無 & 8.6 \\
\hline $\mathrm{D}$ & 60 & 男 & 31.9 & 185 & 無 & 10.3 \\
\hline $\mathrm{E}$ & 58 & 男 & 23.2 & 6 & 有 & 7.4 \\
\hline $\mathrm{F}$ & 55 & 女 & 28 & 6 & 有 & 9.8 \\
\hline G & 70 & 男 & 24.7 & 60 & 無 & 7.1 \\
\hline $\mathrm{H}$ & 39 & 男 & 22.8 & 10 & 無 & 9.1 \\
\hline I & 60 & 女 & 16.8 & 6 & 無 & 6.7 \\
\hline $\mathrm{J}$ & 71 & 男 & 22.8 & 69 & 無 & 9.6 \\
\hline $\mathrm{K}$ & 61 & 男 & 21.3 & 108 & 有 & 8.3 \\
\hline $\mathrm{L}$ & 71 & 男 & 22.6 & 6 & 無 & 10.5 \\
\hline M & 52 & 男 & 25.4 & 6 & 有 & 8.2 \\
\hline $\mathrm{N}$ & 78 & 女 & 29.4 & 92 & 無 & 12 \\
\hline $\mathrm{O}$ & 54 & 女 & 26.1 & 40 & 無 & 9.3 \\
\hline $\mathrm{P}$ & 61 & 女 & 34.8 & 99 & 無 & 8 \\
\hline 平均値 $\pm \mathrm{SD}$ & $61.3 \pm 10.0$ & & $25.4 \pm 4.8$ & $72.4 \pm 114.5$ & & $9.0 \pm 1.4$ \\
\hline
\end{tabular}


2. 方法

調查方法は，身体活動量を測定する質問紙法の妥当性 を検証する方法としてスズケン社製生活習慣記録機ライ フコーダ GS/Me（以下 LC）を使用した，LCは，腰部に 装着して身体にかかる加速度から運動強度を記録し，時 間と体重を加味して消費エネルギーを測定することが可 能である。精度, 利便性の面に扔いて身体活動量の優れ た評価方法の 1 つであり，身体活動に関する質問紙法の

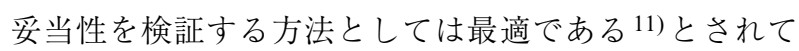
いる. 調查内容を理解し同意が得られた協力者にLCを 貸し出し，1 週間の身体活動量 (total physical activityLC : 以下 TPA-LC）を測定した。な扔入浴時や就寝時に は外し，それ以外の時は常に装着するように指導した。 また， LC 返却の際に簡単な聞き取り調査を行うことの みを伝え, IPAQについての説明は一切行わなかった。 そして, IAPQ日本語版の SVを使用し， LC 返却時に面 接法にて回答を得て, 1 週間の身体活動量 (total physical activity-IPAQ：以下 TPA-IPAQ）を算出した.

統計解析はTPA-LC と TPA-IPAQの比較に対応ある $\mathrm{t}$ 検定を行い，さらにPearsonの相関倸数を算出した，統 計処理にはIBM SPSS Statistics 18 を使用し, 統計学的 な有意水準は $5 \%$ 未満とした。

倫理的配慮として, 研究を行う上ですべての研究協力 者に対し研究の主旨, 匿名性の確保, 自由参加であり調 査を拒否された場合でも不利益を被らないこと, 同意撤 回の自由などを, 文書と口頭で説明し, 文書により研究 協力の同意を得た。な拉, 本研究の計画は, 茨城県立医 療大学倫理委員会 (受付番号 393) 拈よび土浦協同病院倫 理委員会 (受理番号201)の承認を得た研究である.

\section{III. 結 果}

対象者の全てが脱落することなく, TPA-LC と TPAIPAQを算出できた，対応あるt検定の結果，TPA-LCが 平均 $1461.4 \pm 595.4 \mathrm{kcal}$, TPA-IPAQが平均 $1443.6 \pm$ $902.5 \mathrm{kcal}$ と両群間で有意な差を認めなかった。また Pearsonの相関係数を算出した結果, 両変数間の相関係 数は 0.69 の有意な高い相関を認めた(表 2 ).

\section{IV. 考 察}

定期的な身体活動は，機能障害や死亡率，慢性疾患の 発症を減少させることが可能であり健康的な加齢にとっ て必要不可欠である ${ }^{15)}$ ，特に慢性疾患の一つである糖 尿病発症後の患者に执いて, 如何に身体活動量を獲得す るかが大きな課題である 9,10$)$.

本調査では，高齢者を含み，さらに身体活動量の低下 も予測される糖尿病患者の身体活動量評価への適用の検 討を目的に, IPAQの妥当性を検討した，分析の結果から，
表 2 LC-EEC と IPAQ-ECC の值

\begin{tabular}{cc}
\hline LC-EEC $(\mathrm{kcal})$ & IPAQ-ECC $(\mathrm{kcal})$ \\
\hline $1461.4 \pm 595.4$ & $1443.6 \pm 902.5$ \\
\hline LC-EEC と IPAQ-ECC の相関係数 & $\mathrm{r}=0.69^{*}$ \\
\hline & $* \mathrm{p}<0.01$
\end{tabular}

TPA-LC と TPA-IPAQ の両者の平均值に有意差を認めず， Pearsonの相関分析では，両変数間に高い相関が得られ た，そのため, 糖尿病患者でもライフコーダと同等の身 体活動量を算出可能なことが確認されたことにより, IPAQ 糖尿病患者の身体活動量の評価に用いることの 妥当性が示されたものと考えた。

本研究と同様にLCを使用し行われた先行研究 ${ }^{11) て ゙ は, ~}$ 標本数や対象者の平均年齢などに違いはあるが，相関係 数がSVでは 0.37 と低值であり, 本研究の方が高い相関 関係を示した。これについては, 今回の対象者の平均年 齢が 60 歳代前半と比較的年齢層が高く先行研究の 20 歳 代から 30 歳代の対象者と比べ, ライフスタイルや身体 活動が複雑化して㧍らず想起しやすい状態に繋がったこ とが一つの要因として考えられた。また, 記憶の問題を 配慮し全例面接法にて実施したことが二つ目の要因とし て考元られた。中高年者や後期高齢者に対し調查を行う 場合, 記憶の問題や質問項目への理解が得られるような 配慮をすることや扶養家族または介護者から聴取するこ となどの調査方法の検討が必要であると考えられた。

身体活動量の評価手段としては歩数計や加速度計, 質 問紙法などによる評価が臨床で主に用いられる，歩数計 や加速度計は, 客観的な指標で評価が可能で使用者の不 快感が少なく, 日常生活で使用しやすいため主要な道具 として用いられてきた。しかし, 調査者や協力者は機器 管理の問題や時間的な制約を課してしまうこと, 準備等 にかかる費用の面に扔いても大きな負担を受けるため, 大規模な疫学研究に適応できない 16$)$. 一方, 質問紙法 については, 短時間での評価が可能で, 対象者の日常の 身体活動を長期的にも評価でき, 臨床で非常に導入しや すい特徴がある ${ }^{17)}$ ，質問紙法であるIPAQは，器具を用 いることなく短時間の実施が可能で, 安価で導入しやす いため, 対象者の日常生活の身体活動の長期的な評価に も活用ができる。

しかしながら，今後糖尿病患者にIPAQの適応を検討 する場合には，IPAQに起因する過小評価と過大評価の 点について配慮する必要がある13)，過小評価については， 調査として少なくとも 10 分以上の身体活動を行った内 容について協力者に報告をさせている点である，従って， 10 分未満の身体活動については反映されない，そのため, 虚血性心疾患や脳血管疾患, 骨関節疾患等の問題により, 持続した身体活動が不可能な患者に対しては適応となり 
難く，身体活動の評価には別の手段を検討する必要があ る，対照的に，過大評価については，協力者が身体活動 を行った頻度や期間を過㮃報告する可能性がある。記憶 想起の問題は高齢者で一般的であるが, 糖尿病患者は男 女とも年齢が高くなるとともにその割合が高くなり, 70 歳代以上でも男性が $37.4 \%$, 女性が $28.3 \%$ と報告さ れている ${ }^{18)}$ ，更に，糖尿病患者は，非糖尿病者と比べ 認知症の発症が高い可能性 ${ }^{19)}$ があるため, 過大評価し やすい傾向にあることを配慮すべきである，今後，調査 研究など行っていく際は, 認知機能に対する客観的な評 価を行った上で開始される必要がある。

今回, 糖尿病患者でもほぼ正確に身体活動量の評価が 可能であることが明らかにされたことで，今後は糖尿病 患者を対象としたコホート研究に扔いても活用が可能な ものと思われた，そして，今後IPAQから算出される身 体活動量を指標とした分析により，糖尿病患者に扔ける 身体不活動を規定している要因を明らかにし，身体活動 量の向上を図るためのより有効な介入を計画することが 可能と考えられた.

謝辞 日頃から本研究を進めるにあたり多大なご協力と ご支援を頂きました総合病院土浦協同病院内分泌内科今 井泰平先生，清水馨先生を始めとした医局スタッフの皆 様，看護部内科外来スタッフの皆様，リハビリテーショ ン部スタッフの皆様には心より感謝申し上げます。

\section{引用文献}

1) WHO : Prevalence of diabetes world wide. http://www.who. int/diabetes/facts/world_figures/en/(閲覧日2011年12月 1日).

2) 穴迫唯衣, 曽根博仁：運動と糖尿病のかかわりにせまる一 糖尿病の一次予防・二次予防に打ける身体活動·運動の意 義一. Life Style Medicine, 2010， 4(3): 197-203.

3) $\mathrm{Hu} \mathrm{FB}$, Stampfer MJ, Solomon C, et al.: Physical activity and risk for cardiovascular events in diabetic women. Ann Intern Med, 2001, 134(2): 96-105.

4) Wei M, Gibbons LW, Kampert JB, et al.: Low cardiorespiratory fitness and physical inactivity as predictors of mortality in men with type 2 diabetes. Ann Intern Med, 2000, 132(8): 605-611.

5) Edward WG, Robert BG, Carl JC, et al.: Relationship of Walking to Mortality Among US Adults With Diabetes. Arch Intern Med, 2003, 163: 1440-1447.

6) Egede LE, Zheng D: Modifiable cardiovascular risk factors in adults with diabetes:prevalence and missed opportunities for physician counselling. Arch Intern Med, 2002, 162: 427-433.

7) Ford ES, Herman WH: Leisure-time physical activity patterns in the US diabetic population. Findings from the 1990 National Health Interview Survey-Health Promotion and Disease Prevention Supplement. Diabetes Care, 1995, 18: 27-33.

8) Nelson KM, Reiber G, Boyko EJ: Diet and exercise among adults with type-2 diabetes (findings from NHANES III). Diabetes Care, 2002, 25: 1722-1728.

9) Karlijn DG, Delfien VD, Benedicte D, et al.: Physical environmental correlates of self-reported and objectively assessed physical-activity in Belgian type 2 diabetes patients. Health and Social Care in the Community, 2010: 1-11.

10) Dutton GR, Provost BC, Tan F, et al.: A tailored print-based physical activity intervention for patients with type 2 diabetes. Preventive Medicine, 2008, 47: 409-411.

11) 村瀬訓生, 勝村俊仁, 上田千穂子 ·他 : 身体活動量の国際 標準化一IPAQ 日本語版の信頼性, 妥当性の評価一。厚生 の指標, 2002, 49(11): 1-9.

12) Craig CL, Marshall AL, Ainsworth BE, et al. : International physical activity Questionnaire: 12-country reliability and validity. Med Sci Sports Exere, 2003, 35(8): 1381-1395

13) Tomioka K, Iwamoto J, Saeki K, et al.: Reliability and Validity of the International Physical Activity Questionnaire (IPAQ) in Elderly Adults: The Fujiwara - kyo Study. J Epidemiol, 2011, 21(6): 459-465.

14) 北村菜月, 佐藤 拓, 川越厚良・他：若年健常者の日常 生活における身体活動量の評価一IPAQ日本語版の信頼 性・妥当性の 3 軸加速度計を用いた検討一. 理学療法科学, 2010, 25(5): 767-771.

15) Nelson ME, Rejeski WJ, Blair SN, et al.: Physical activity and Public health in older adults: recommendation from the American College of Sports Medicine and the American Heart Association. Circulation, 2007, 116: 1094-1105.

16) Washbum RA, Montoye HJ: The assessment of physical activity by questionnaire. Am J Epidemiol, 1986, 123: 563-576.

17) 山村千晶, 田中茂穂, 柏崎 浩・他：身体活動量に関す る質問表の妥当性について. 栄養学雑誌, 2002, 30(6): 265-276.

18) 厚生労働省. 平成 14 年度糖尿病実態調查. 2003.http:// www.mhlw.go.jp (閲覧日 2012年9月14日).

19) Biessels GJ, Staekenborg S, Brunner E, et al.: Risk of dementia in diabetes mellitus: a systematic review. Lancet Neurol, 2006, 5(1): 64-74. 